\title{
O INVERSO DO EMBRIÃO: REFLEXÕES SOBRE A SUBSTANCIALIDADE DA PESSOA EM BEBÊS PREMATUROS *
}

Igor José de Renó Machado

\section{Introdução}

Para expor uma reflexão sobre o papel da substância na atribuição de pessoalidade aos bebês e fetos, analiso neste texto três eventos significativos em três distintos pontos do processo de desenvolvimento do embrião. Trato de um caso liminar, no qual a existência de pessoa no recém-nascido é fruto de embates e tensões: um nascimento prematuro de 30 semanas, com baixo peso. Também outro caso em que, apesar do nascimento prematuro e da internação, não houve baixo peso e nem embates em torno da pessoalidade do recém-nascido. E, por fim, um caso de aborto espontâneo, no qual o feto não foi considerado pessoa e não houve embates sobre este fato.

Estes três eventos permitem mapear outra dimensão dos processos de atribuição de pessoalidade aos fetos e bebês na nossa sociedade: o papel que a noção de substância - entendida aqui como substância corporal, materialidade, peso - apresenta nos processos de pessoalização. Analiso uma lógica nativa de pessoa e substância exercida pelas funcionárias da UTI neonatal e o confronto com um processo social de construção de pessoa por parte do casal $^{1}$ que gera o bebê.

Tal processo tem sido estudado de múltiplas formas e há certo consenso de que nas "sociedades ocidentais" a existência da pessoa tem sido antecipada gradualmente com o avanço da técnica de exames pré-natais e de concepção (Strathern 1992; Salem 1997; Luna 2001, 2007, entre outros). O ultrassom tornou-se um marco definitivo de instituição da pessoa, por dar forma, imagem e sexo ao bebê (Chazan 2007). Por outro lado, as tecnologias de reprodução avançaram até o ponto da criação de novos entes sociais, como o embrião congelado. Esse processo levaria a existência da pessoa para os estágios iniciais da fecundação e o ciclo de vida se iniciaria, portanto, muito cedo. 
Neste artigo pretendo demonstrar que existem processos que se contrapõem à antecipação de atribuição de pessoa. Há outros índices que também compõem a imaginação do que seja ou não uma pessoa. No caso deste artigo, o índice de contraponto é a noção de substância, na forma como era construída pelas trabalhadoras da UTI e pela própria burocracia do hospital.

Quero, portanto, afirmar que os processos de construção de pessoa não estão restritos e fadados a uma antecipação, mas que são contrastados por outras formas de construir a pessoalidade de bebês e fetos e, para isto, indico haver certa fluidez, tensão e disputa entre os índices utilizados para que seja dada tal atribuição. Esse momento liminar - a dúvida sobre a pessoa - aconteceu dentro da UTI neonatal, ela mesma um espaço intensamente liminar.

Para atingir tais objetivos, apresento uma rápida discussão sobre pessoa, indivíduo e processos de desenvolvimento, com a única intenção de destacar a argumentação de Strathern (1992), que espero matizar ao longo do texto. A seguir avanço na descrição etnográfica dos três casos. Esta descrição é marcada por uma reflexão sistemática sobre os processos narrados, antecipando o que a parte final do texto reafirmará: a importância de uma lógica substantiva para a atribuição de pessoa nas concepções nativas da UTI neonatal.

\section{Pessoa e bebês}

A produção social da criança não é apenas a criação de mais uma pessoa, mas a redefinição das relações entre os que estão diretamente envolvidos. Como afirma Pina-Cabral (2005), temos uma produção coletiva que altera todas as posições originais. Indo um pouco mais adiante, poderíamos dizer que, além de alterar as relações dos entes envolvidos, a produção social da pessoa muda também a qualidade dos entes. Uma mulher torna-se mãe, o homem, pai. Essa passagem não é uma simples mudança de estado, mas uma reformulação relacional da constituição da pessoa do ente à medida que a nova pessoa vai se concretizando. Como afirma Lévi-Strauss, a nomeação é sempre uma classificação, seja de quem é nomeado ou de quem nomeia:

[...] estamos, então, em presença de dois tipos extremos de nomes próprios entre os quais existe toda uma série de intermediários. Num caso, o nome é uma marca de identificação que confirma, pela aplicação de uma regra, a dependência de um indivíduo que se nomeia a uma classe pré-ordenada [...]; no outro caso, o nome é uma livre criação do indivíduo que nomeia e que exprime, por meio daquele que ele nomeia, um estado transitório de sua própria subjetividade. Mas 
poder-se-ia dizer que, tanto em um quanto em outro caso, verdadeiramente se nomeia? A escolha, parece, só está entre identificar o outro, determinando-lhe uma classe ou, a pretexto de lhe dar um nome, identificar a si mesmo através dele. Portanto, nunca se nomeia, classifica-se o outro, se o nome que se the dá é função das características que possui; ou classifica-se a si próprio, se se acreditar dispensado de seguir uma regra, e nomeia-se o outro "livremente", ou seja, em função dos caracteres que se possui. E, no mais das vezes, fazem-se as duas coisas ao mesmo tempo (Lévi-Strauss 1989 [1962]:204).

De acordo com esta perspectiva, percebemos que a qualidade de ser pessoa é relacional, um novo ser que se vê inserido em uma teia de relações. Mas quando pensamos em pessoa nas sociedades ocidentais ou euro-americanas (para usar uma categoria de M. Strathern), ${ }^{2}$ é consenso identificar o indivíduo como categoria de pessoa no "Ocidente". Mauss, em seu trabalho clássico, institui essa teleologia que vai da persona ao indivíduo, num processo histórico. A qualidade do indivíduo seria a sua distintividade e a sua separação das relações sociais. O indivíduo existe apesar das relações sociais.

Trabalhos sobre a noção de pessoa ocidental indicam essa qualidade supostamente autônoma do indivíduo (Dumont 1985). Poderíamos dizer que há um contraste entre situações em que a pessoa é eminentemente social e não existe fora deste contexto, em sociedades não ocidentais, e aquelas em que a pessoa é um indivíduo e independe das relações sociais para existir. Neste caso, poderíamos construir uma oposição entre pessoa e indivíduo, embora este último possa ser tomado por uma categoria nativa de pessoa, ou seja, o indivíduo como categoria sociológica de pessoa é, de certa forma, o oposto de categorias de pessoa que são relacionais.

Este pequeno preâmbulo serve para demonstrar que a relação entre pessoa e indivíduo enquanto categorias tidas como opostas, e a de pessoa e indivíduo como modalidades da categoria de pessoa são complexas. O que é exatamente o indivíduo e o que é exatamente a pessoa? Variam as definições conforme os autores. Aqui não é o lugar para se fazer uma historiografia dessas definições, que podem ser encontradas em outros textos (Dias Duarte 1983, 1986; Goldman 1996; Seeger, DaMatta \& Viveiros de Castro 1979 etc.). Para a operacionalização deste texto, tomo como parâmetro a discussão de Strathern (1992) sobre a constituição, no pensamento ocidental, de uma ideia de processo de desenvolvimento do feto (bebê, criança), tido como natural e, como decorrência do fato natural, a noção de "individualidade", que seria um ponto no processo de desenvolvimento no qual o feto (ou embrião, bebê, criança) seria indivisível e, a partir de então, uma entidade individual com as condições necessárias para o estabelecimento da pessoa (:21). 
Desta forma, a noção de pessoa teria sido tão autonomizada da vida social que atualmente a individualidade é uma questão a se resolver de maneira natural no correr do processo de desenvolvimento de um novo ser. Importante destacar que Strathern fala apenas em pessoa, não em indivíduo, fazendo uma opção por tratar a categoria euro-americana de pessoa não como um conceito, mas sim descrevendo-a com sua característica principal, no caso, a individualidade.

Assim, é a condição de ser independente das relações sociais, indivisível, que confere ao novo ser o estatuto de pessoa. Esta condição pode ser resumida em uma individualidade. Passa-se de essências para processos. Mas, como indica Goldman (1996), acredito que as práticas de constituição de pessoa na "sociedade ocidental" não são apenas e exclusivamente relativas à autonomia do novo ser quanto às relações sociais. A partir da descrição que apresento a seguir, procuro refletir sobre uma tensão entre esta perspectiva "isolacionista" da individualidade e perspectivas mais relacionais de constituição da pessoa nos novos seres em nossa sociedade. Adoto, então, os termos individualidade e pessoalidade como formas distintas de constituição da condição de pessoa: a primeira autônoma no que diz respeito às relações sociais, e a segunda, não. Penso as duas como formas de conferir realidade aos novos seres, porém distintas e às vezes contraditórias.

Segundo Strathern, as novas tecnologias de reprodução (NTR) afetaram as noções de parentesco. A reprodução assistida, por exemplo, é a produção de pessoas e, especialmente, de pessoas individuais. "[O] resultado paradoxal é que facilitar o processo não facilita automaticamente a criação de pais. [...] O que é assistido é a produção de pessoas e especificamente da pessoas individuais" (Strathern 1992:21). ${ }^{3}$

Em que ponto há um ser humano, o estabelecimento da pessoa, com potencial para clamores morais sobre outros? Para os euro-americanos, a individualidade é biologicamente produzida como um processo natural de reprodução. Não são as relações com outros sujeitos, mesmo os pais, que afetam o modo como a pessoalidade é construída, mas o processo natural de reprodução automática. Discute-se em que ponto desse processo se pode falar em individualidade. Dessa forma, "[A] noção de pessoa aparece como um desenvolvimento natural" (Strathern 1992:23). Para a autora, a pessoalidade é antecipada, e mesmo a reprodução de pessoas é, de certa forma, não relacional. "Neste diálogo conduzido em relação ao ser ainda não nascido, a emergência da pessoalidade, ela mesma, foi tomada como um processo natural, o resultado de um desenvolvimento biológico ao invés dos posicionamentos morais da própria pessoa ou da participação em relacionamentos com outras pessoas" (Strathern 1992:23). Não há relação entre as pessoas, 
mas um processo natural, cujo resultado é um ser individual, possuidor de direitos devido à transmissão de substância pelos pais.

Então, a biologia predomina e a pessoa começa quando um fato biológico se inicia, ou seja, o predomínio crescente da biologia levará à conjunção de individualidade e pessoa no surgimento, concomitante, do embrião como detentor de direitos. Para Strathern, o que as NTR fazem é sobrepor o valor da biologia e antecipar para o momento da criação da individualidade biológica o processo de pessoalização. A autora aponta que as relações sociais parecem contingentes nas NTR, tanto que se instaura a possibilidade legal da existência de uma criança sem pai, no caso da doação de sêmen, uma espécie de direito legal de negar a biologia.

O desenvolvimento não é só de uma condição para outra, de embrião para pessoa, pois as circunstâncias originais são relevantes. No caso, um conjunto de células não abrange a descrição do ser inteiro, já que o ser humano é mais que um conjunto de células. A segunda entidade (a pessoa) é de ordem diferente da primeira (embrião), abarcando uma ordem diferente de si mesma. Acontece o mesmo com a linguagem no debate público sobre embriões: uma passagem da linguagem cultural para a linguagem natural. Apenas em certo momento do processo de desenvolvimento é apropriado falar de "pessoa", já que degraus de complexidade "natural" levam a degraus de interpretação cultural/social.

Quando é possível reconhecer numa forma natural a presença de outra, social? A pessoa contém em si a distinção entre célula e pessoa, a célula, não eis a assimetria. Strathern passa então a discutir a assimetria contida na noção particular de desenvolvimento ou processo. A sequência cumulativa pode ser apresentada como uma questão de construção da forma, que é uma forma de adição. Neste contexto, a ciência opera como descritora de fatos e não de opiniões. Os problemas são permeados por uma noção de complexidade, e a questão de grau (descontinuidade entre estágios) pode ser subsumida à idéia de que qualquer estágio é o resultado de um processo de complexificação (Strathern 1992:143), que acaba tornando contínuo um fluxo de célula para pessoa e encobre as partições entre fato (natural) e interpretação social.

Seja social ou legalmente, por contraste com a criança, a parentalidade é sempre construída como um objeto do conhecimento. Assim, a relação entre pais e crianças funciona como um híbrido, um tipo de amálgama de diferentes ordens de fatos. Se olharmos para a relação entre os pais, nós encontraremos um híbrido similar. Entre pai e mãe, a mãe é reconhecida, enquanto o pai é construído: "a mãe é constituída na sua relação com a criança, enquanto o pai é constituído na sua relação com a mãe" (Strathern 1992:148). 
São diferentes os estágios no envolvimento da mãe com a criança. Cada um é construído no anterior, e "a mãe [...] é o resultado híbrido da complexificação" (Strathern 1992:149). Ela contém evidências de fatos naturais e culturais e passa do estado natural (fertilização) para outro social (papel de mãe). A criança reproduz dois tipos de pais: um que representa a natureza, e outro, a cultura. Mas não são partes divisíveis de uma mesma coisa, "antes, eles são enxertados um no outro, na perspectiva de uma sequência de desenvolvimento de um processo biológico/cultural, de tal forma que a criança completa é a construção cultural ou social de um fato natural" (Strathern 1992:156). O desenvolvimento do embrião não é apenas crescimento, porque a cada ponto manifesta um diferente conjunto de potenciais para o seu futuro social e natural e estes nunca têm peso igual, são sempre assimétricos.

Destaco aqui esta perspectiva que liga a pessoalidade a um processo natural de desenvolvimento no que tange às sociedades euro-americanas. Esse processo de desenvolvimento tido como uma sequência de complexificações é importante para discutirmos a seguir o prematuro. Assumindo a validade desta argumentação, espero demonstrar, entretanto, que essa concepção naturalizada de pessoa (a-relacional) convive com outras formas que são relacionais. A hipótese a ser avançada é a de que o nascimento de um bebê prematuro coloca em evidência a existência de percepções distintas de pessoa. Passemos agora à descrição etnográfica.

\section{UTI neonatal como espaço liminar}

A análise que segue deriva da minha experiência pessoal, ${ }^{4}$ referida tanto à internação da minha esposa no período pré-parto (uma semana) como ao período que se seguiu ao parto de nosso primeiro filho e sua subsequente internação por 21 dias na UTI neonatal, devido ao nascimento prematuro. O "campo" teve seguimento no nascimento do segundo filho, dois anos depois, quando ele permaneceu por nove dias na mesma UTI neonatal. Por fim, apresento uma experiência de curetagem da terceira gravidez, que não seguiu adiante. As internações dos bebês aconteceram num hospital para classe média em Ribeirão Preto, SP. A curetagem se deu em outro hospital, também para classe média, na mesma cidade.

\section{A UTI Neonatal}

Antes, uma descrição rápida do espaço e do hospital referentes aos períodos 
de observação. É, antes de tudo, um hospital de classe média, que atende a convênios amplos, como Unimed, Cassi etc. Sua maternidade é relativamente pequena: são três quartos duplos e um quarto single. A lotação máxima, portanto, é de sete mães. A maternidade corresponde ao fim de uma ala no segundo andar do hospital e é demarcada por uma porta que especifica: "maternidade, entrada restrita aos funcionários e usuários". Os quartos ficam todos do lado esquerdo. À direita estão, nesta ordem, uma pequena secretaria, uma sala de consultas, uma sala maior com dois leitos, onde ficam as mães antes de seguirem para a sala de partos, contígua a esta. Assim, as funções burocráticas e médicas estão à direita e as mães, à esquerda.

Logo a seguir, fechando a ala desta parte do prédio, encontra-se a UTI neonatal, que ocupa toda a extensão do fim do corredor, estando, portanto, dos dois lados do corredor. A sala de parto vai um pouco além do limite dos quartos, tendo uma porta de saída que está em frente à porta da UTI neonatal, providencialmente para casos de urgência, mas também de rotina. Os bebês são levados da sala de parto para a UTI, onde passam pela limpeza e recebem os primeiros curativos no umbigo. A UTI conta, assim, com duas partes. Ela forma um "L": uma parte ocupa a extensão dos dois corredores e é a UTI neonatal propriamente dita (onde ficam os leitos); a "lateral" do Lé uma continuação da parte esquerda da maternidade (os quartos), separada por uma porta que sempre está aberta. Neste espaço ficam os bebês "nascidos a termo" e "saudáveis", que podem ser vistos por uma grande parede de vidro. É o lado público da UTI; os bebês ficam ali por pouco tempo e logo passam ao quarto das mães.

A UTI segue assim a lógica da maternidade como um todo: à esquerda, as mães e os bebês saudáveis; à direita, os espaços médico-burocráticos; atravessando as duas fronteiras, muito propriamente, está a UTI, como área evidentemente liminar. Todos os pais de filhos prematuros aguardavam ansiosamente a hora de ver seus filhos na parte "pública" da UTI, sinônimo de saúde e de coincidência da pessoa do bebê com sua substância corporal. ${ }^{5}$ A parte dos leitos dentro da UTI está dividida em três espaços: à esquerda, temos quatro incubadoras para casos mais graves; à direita, mais dois leitos para casos intermediários; na extrema direita, um pequeno quarto onde dormem os/as médicos/as de plantão. A divisão do espaço para casos mais graves e menos graves é relativa e depende do número de bebês, obviamente. Se houver cinco bebês que inspiram mais cuidados, eles estarão divididos entre os dois espaços. Mas sempre a passagem do quarto à esquerda para o quarto à direita era entendida pelos pais como uma melhora, mesmo que os médicos dissessem que o estado dos bebês era o mesmo. Assim, o espaço é fundamental na marcação do status de pessoalidade que o bebê recebe do hospital, o que é entendido de uma forma imperiosa pelos pais, posso dizer. 
Curiosamente, a área interna da UTI inverte a lógica do resto da maternidade e parte pública da UTI: mais "saúde" está à direita, e não à esquerda. Isto acontece por motivos práticos (a disposição dos espaços dentro da UTI é favorável a que os quatro leitos mais sensíveis fiquem à direita), mas pode ser também uma condição do espaço liminar que as lógicas fiquem pendentes e a inversão sirva para introduzir o que Pina-Cabral (2005) chama de uma "suspensão" da pessoalidade da criança, ao embaralhar o esquema até então adotado.

Foi, de fato, o que sentimos de forma muito sensível nos nossos "dias de UTI". Passo agora a narrar a primeira situação que inspirou a escrita deste texto e que foi citada por Pina-Cabral em sua conferência de abertura do PPGAS da Unicamp (2005).

\section{Primeira experiência}

Ao nascer prematuro, o nosso bebê, Gabriel, foi imediatamente internado na UTI, no lado "mais grave". Nasceu com cerca de 1,6 kg, ao fim de 30 semanas. Os primeiros dias foram terríveis: a necessidade de ficar entubado, a incubadora com alto nível de oxigênio (que pode trazer danos à visão do bebê), a pneumonia aspirativa, o baixo peso.

Todos esses problemas eram monitorados com exames sucessivos, sistemáticos e doloridos. Gabriel permanecia com sonda oral para alimentação, duas sondas intravenosas para alimentação e medicação e mais uma gama de sensores para monitorar batimento cardíaco, temperatura e respiração. De certa forma, todos os problemas são relacionados com o baixo-peso, seja direta ou simbolicamente. A pouca substância do bebê indicava uma pessoa não formada e, portanto, sujeita a não completar o "primeiro" ciclo de um nascimento sadio.

Na lógica burocrática do hospital, a forma de resolver esse impasse entre substância e pessoa era não considerar o bebê como pessoa - o que seria evidenciado pela atribuição do nome que a família lhe deu — e tratá-lo oficialmente como uma extensão da substância da mãe, sem pessoalidade. Desta forma, o bebê era chamado de RN Sônia Silva. RN é a sigla para "recém-nascido" e evidencia também a vontade de "suspender" o processo de criação da pessoa, pois não se trata do filho de Sônia Silva, mas do RN Sônia, assim, com as iniciais e o nome da mãe. Para o hospital, portanto, o Gabriel "para-nós" não existia, mas apenas o RN Sônia Silva, evidência de um descompasso entre substância e pessoa.

Este é o primeiro grande choque simbólico para pais de bebês prematuros: verem-se diante de uma negação da pessoa do filho, que já vinha sendo 
cultivada desde a ciência da gravidez, consolidada na constatação do sexo e nos diversos exames. É praxe, inclusive, gravar o exame de ultrassom e exibi-lo a amigos, como uma filmagem do filho - já pessoalizado, concreto, com substância (Chazan 2007). Mas o perigo limite do nascimento prematuro faz o hospital, por sua conta, suspender esse processo, como enfatiza Pina-Cabral. Nós, como pais, diante desta situação, só podíamos sofrer, no "limiar de nossos afetos".

Obviamente que, para nós, o processo de suspensão do hospital não operava: ele era sempre $O$ Gabriel, nosso filho já desde a gravidez. O contraste evidente se materializava na ficha de internação de Gabriel: neste papel, que ficava acima da incubadora onde estava nosso filho, constavam os dados referentes ao nascimento e o "antinome" RN Sônia Silva. Um nome que não poderia ser entendido por nós e que causava uma estranheza que só a reflexão posterior viria a traduzir. Aquele epíteto atribuído pelo hospital significava o perigo que Gabriel corria, na verdade.

Mais impressionante que a lógica burocrática, porém, foi constatar que as trabalhadoras da UTI ${ }^{6}$ também o chamavam de "RN Sônia", como forma de se defenderem da liminaridade dos bebês. O "antinome" virava, assim, uma parede atrás da qual se escondiam os profissionais para se protegerem do turbilhão de emoções que a UTI gerava cotidianamente - uma parede que nós, pais, tínhamos que escalar e ultrapassar com nosso pequeno filho. Sempre nos chocava quando a enfermeira que recepcionava as visitas nos anunciava: "os pais do/a RN Sônia chegaram".

Outra evidência dessa suspensão temporária imposta pelo hospital e por seus trabalhadores estava na indefinição do sexo do bebê para estes últimos. Como se sabe, um dos passos na construção da pessoa do bebê é a constatação do sexo e a atribuição do nome, para "dar personalidade", como cita Pina-Cabral. Como índice de pessoalidade, o gênero do bebê era propositalmente trocado pelas trabalhadoras. Ora se referiam ao Gabriel como "ele", ora como "ela". Quando reclamávamos do "ela", diziam-nos: "é ela porque é 'a' criança...".

Assim, qualquer evidência de que nosso bebê era uma pessoa foi sistematicamente negada pelo hospital e seus trabalhadores - ao menos enquanto ele não tinha substância necessária para ser visto como pessoa. O cotidiano da UTI envolvia uma pesagem constante e obsessiva das crianças: pesavam-se o bebê e as fraldas sujas, faziam-se cálculos sobre o ritmo de aumento do peso. Tantas gramas por dia era bom, outras tantas era pouco etc. Nós acompanhávamos o aumento de peso com um fervor religioso, mesmo sendo agnósticos.

A linha que atribui pessoa em relação à substância é tênue e relativa. Para os trabalhadores da UTI, nosso bebê virou pessoa e ganhou seu próprio nome 
de volta quando completou 1,850 kg. Mais ou menos neste marco "substantivo", aquela ficha que nos atormentava e lhe atribuía um antinome virou um motivo de alegria. Chegamos para a visita e lá estava escrito a caneta, acima dos dados, o nome Gabriel. Era a confissão das trabalhadoras para nós que Gabriel estava indo bem e que agora elas não precisavam mais se "defender" do seu nome. O hospital, porém, continuou a tratá-lo como RN Sônia Silva até o fim de sua internação. Pouco depois, aos dois quilos, ele teve alta ainda como RN Sônia. O hospital, assim, "lava as mãos" até o fim.

Outra liminaridade imposta pela UTI é a mudança do cotidiano dos pais. São duas mudanças simetricamente inversas: não se volta para casa com seu filho nos braços e, por isso, de certa forma, muda-se para o hospital. Há uma suspensão também, no lar de origem, na construção do espaço do bebê. A rotina imposta pelo hospital era rígida. De três em três horas o bebê precisava mamar e deveria receber o máximo de leite da mãe. A ordenha da mãe deveria ser feita no hospital, ou seja, cerca de uma hora antes, o casal deveria se encaminhar ao hospital. Ao longo do dia eram oito mamadas, e em seis delas deveríamos estar presentes (os pais são liberados das mamadas noturnas, quando o bebê recebe leite especialmente fabricado para prematuros). Passávamos de seis a oito horas por dia, ao menos, dentro do hospital. Havia apenas dois horários de visita: às 15 h e às 20h. Podia-se ficar uma hora com o bebê nas visitas.

Alguns pais, vindos de outra cidades, mudavam-se para Ribeirão Preto no período de internação dos filhos. Outros passavam o dia inteiro no hospital e apenas voltavam a casa para dormir. Essa redistribuição do horário implica uma suspensão do próprio cotidiano, marcando tanto a centralidade do processo de maternidade e paternidade como uma preparação para uma possível perda: distancia-se do lugar do filho, previamente construído no seio da casa.

Nossa história acabou bem. Gabriel desenvolveu-se a contento, saiu do hospital sem sequelas aos dois quilos e 21 dias. A produção da substância nas ordenhas, o cuidado nas visitas, o acompanhamento do trabalho dos médicos, a busca de informações sobre prematuridade, tudo transcorreu com muito sofrimento mas, como se diz, dos males, o menor. Ficou a nítida impressão que todo o processo foi uma luta coletiva, física e simbólica pela concretização da pessoa do bebê.

\section{Segunda experiência}

A segunda experiência foi o nascimento de meu segundo filho, David, também prematuro, mas com muito mais peso. Tecnicamente, a prematuridade 
dele era de apenas duas semanas, o que possibilitou que tivesse um peso considerado normal para bebês nascidos a termo. Tinha 3,3 quilos. Assim, ele não apresentava ao nascer uma deficiência aparente de substância, seguindo a lógica local das trabalhadoras da UTI. O seu peso fazia dele uma criança normal, portanto. Isso resultou no direito imediato ao nome, ao contrário do que acontecera dois anos antes com o Gabriel. Se a própria individualidade do Gabriel era colocada em questão com a atribuição de um antinome que o caracterizava como substância da mãe, o David teve sua individualidade reconhecida, como resultado de um processo que funcionou. Assim, a construção social da pessoalidade do David, feita em torno da gestação, dos exames pré-natais, do nome escolhido, da montagem do quarto, ou seja, da criação de um espaço social para um novo ser dentro de relações sociais preexistentes, coincidiu com o progresso do processo natural de desenvolvimento substantivo.

Assim, não houve problemas na atribuição do nome. Nenhuma das trabalhadoras o chamou de RN Sônia, embora fosse este o nome escrito em suas etiquetas, o nome burocrático dado pelo hospital. O hospital continuou adotando a mesma prática burocrática de resguardo, uma espécie de suspensão até que o bebê saísse da maternidade para a casa. É como se, enquanto estivesse no hospital, qualquer bebê ficasse sob a tutela exclusiva desta instituição, que é capaz, inclusive, de o nomear de um jeito próprio. $O$ hospital apropria-se completamente do novo ser. Essa capacidade de tomar para si não é sentida pela maioria dos pais que passa apenas uma noite na maternidade e logo segue para casa, onde o bebê recupera o nome social.

Quando o bebê fica mais tempo no hospital, os efeitos da "máquina de captura" são sentidos pelos pais de forma dolorosa, numa queda de braço entre um processo social de atribuição de pessoalidade e as denominações desindividualizadoras do hospital. O interessante é notar que o hospital também compete com o Estado enquanto ente de captura: durante o período de internação tanto do Gabriel como do David, fizemos o registro civil de nascimento, com os nomes que escolhemos para eles. Mas o hospital continuou usando os nomes que ele próprio atribuiu às crianças enquanto "propriedade" dessa máquina.

David, embora com peso "normal", teve um problema respiratório por conta da prematuridade: seus pulmões não funcionavam perfeitamente. Ele necessitava de um complemento mecânico de oxigênio para respirar e isso fez com que ele permanecesse na UTI por nove dias, até que os aparelhos de oxigenação não fossem mais necessários. De certo ponto de vista, ele não tinha completado o processo de desenvolvimento a contento, com seus pulmões ainda "incompletos". Mas isto não era visto pelas funcionárias como 
motivo para não o chamarem pelo nome: elas sabiam que ele ficaria poucos dias na UTI e que sairia sem grandes problemas. Esta situação colocou David numa espécie de dupla liminaridade: era liminar por permanecer na UTI e era liminar por ser grande demais, do ponto de vista das funcionárias, para a mesma UTI. Era como se a evidência de um peso normal — portanto, de completude substantiva - preponderasse sobre qualquer outro ponto de vista. Ele era tratado como uma pessoa doente, não como não indivíduo.

Ficava evidente, constantemente, o discurso de confirmação de grandeza: a todo momento se afirmava quão grande era o David. Todas as funcionárias faziam questão de destacar que ele era "grandão", que estava bem, que tinha muito apetite. As visitas eram pontuadas por expressões de espanto com o seu tamanho. Este fato era tão fora de lugar que ele ficou sozinho, quando possível, em uma das salas da UTI, para evitar que outros pais de prematuros menores tivessem contato constante com ele. O tamanho e, de certa forma, o excesso de substância do David eram uma espécie de ofensa aos pais que tinham filhos em situações mais delicadas e com bem menos peso. Ele gerava uma "inveja" da substância que era conscientemente combatida pelas trabalhadoras através da eventual separação dos bebês dentro do espaço diminuto da UTI neonatal.

Assim, nos termos da lógica nativa da UTI, David era uma pessoa. Havia a constante lembrança de que ele portava substância demais para aquele ambiente e, dessa forma, chegava a ser ofensivo para pais de bebês menores. Mas ele permaneceu por nove dias na UTI e, nesse período, a rotina dos pais sofreu as mesmas alterações: ordenha de três em três horas, exigência da presença nos dois horários de visita, suspensão completa do cotidiano (trabalho, casa etc.). O hospital manteve sua lógica burocrática defensiva e captora.

A principal diferença entre a estadia de Gabriel e a de David era uma qustão de peso, de substância. Entrava em operação o que chamo de "lógica substantiva", ou seja, uma apreciação da individualidade marcada pela quantidade de gramas. É como se o espaço da UTI fosse uma continuidade da barriga da mãe e fosse responsável pela reordenação do descompasso entre o processo tido como natural de desenvolvimento da individualidade e aquele outro social de atribuição de pessoalidade executado pelas famílias. Mas se é uma extensão, é também uma forma de apropriação violenta do processo de desenvolvimento do bebê: contra a mãe, a UTI neonatal assumia para si a função materna, como se fosse uma correção do útero imperfeito da mãe, incapaz de conduzir um processo que deveria ser naturalmente a termo. É, portanto, um espaço híbrido, pois apresenta um conjunto de técnicas e aparelhagens mecânicas para dar seguimento a um processo tido como natural. 
O que dá função à UTI neonatal é ele mesmo um híbrido: o prematuro não é ainda um ser, é a extensão da substância da mãe e é também algo que sobrevive fora e separado da mãe. Esta contradição é expressa na nomeação dos prematuros, que é formalmente uma maneira de dizer que ele está separado da mãe, mas ainda não é um ser individual. Tal condição misteriosa do prematuro revela a lógica substantiva da concepção de pessoa ali articulada: a individualidade vem apenas a partir de certo peso, quando o nome muda. Nesse momento, a individualização (dada por um processo supostamente natural) e a pessoalização (construída relacionalmente pela família) passam a caminhar juntas. A crise do prematuro é justamente expor o descompasso entre esses dois processos.

\section{Terceira experiência}

A nossa experiência pessoal teve ainda mais um capítulo, esse doloroso, por ter sido inconcluso. Tratou-se de um aborto espontâneo, que teve que ser socorrido por uma curetagem, ou seja, o feto faleceu, mas o corpo da mãe não tinha condições de expeli-lo espontaneamente. A curetagem é o ato cirúrgico que realiza essa exclusão do feto falecido no corpo da mulher.

Insiro aqui esta descrição de uma operação para fazer um contraste com as duas outras descrições que revelavam diferentes quantidades de substância em relação ao processo de desenvolvimento tido como natural. Esse evento aconteceu num estágio bem inicial da gravidez. Quais são os procedimentos quando o desenvolvimento do feto é interrompido no começo da gestação? O que é uma fase inicial? Qual estágio de complexificação garante a existência de um ente com direitos legais?

Na legislação brasileira, se o feto morre antes de 20 semanas de gestação, temos um aborto espontâneo. Depois disso, temos um natimorto. O feto resultante do aborto espontâneo não é objeto legal, não precisa ser enterrado e não tem certidão de nascimento. O natimorto implica registro civil, em livro à parte. Caso o feto tenha nascido e permanecido vivo por apenas alguns segundos, não é considerado natimorto e devem ser lavrados os assentos de nascimento e de óbito. ${ }^{7}$ Há, desta forma, separação entre pessoalidade e individualidade, marcada também como um processo natural (nisso Strathern está certa), mas regulado por percepções distintas de substâncias.

O corpo do feto, fruto de um aborto espontâneo, é apenas substância da mãe, que pode ser coletada e descartada - ele se transforma em material de coleta (para exames). Não tem pessoalidade. Muitas vezes um aborto espontâneo necessita de uma intervenção médica para que o feto seja expelido 
(curetagem). O material resultante da curetagem não é pessoa e não precisa ser reconhecido legalmente. Por uma diferença de tempo, após 20 semanas, temos não o aborto espontâneo, mas o natimorto, que tem existência jurídica reconhecida (é pessoa que morreu antes do nascimento, diria). Tem-se a evidência da separação substantiva entre pessoa e não pessoa, medida em termos temporais de um desenvolvimento tido como natural.

Assim, o aborto espontâneo constitui, legalmente, uma espécie de reconhecimento do fracasso do desenvolvimento fetal, resultando em considerações importantes do ponto de vista de suas consequências. O feto não é tido como pessoa, pois não precisa ser reconhecido legalmente, com um registro civil. De certa forma, a legislação determina quando se estabelece o início de uma pessoa, em um processo de complexificação do desenvolvimento. Esse início se dá em torno de 20 semanas. A legislação, entretanto, não determina claramente um ponto no tempo em que o ser gestado se torna individualidade. Ela usa expressões gerais, como "aborto espontâneo", remetendo a sua definição a uma acepção médica. Como a definição médica é sujeita a interpretações, a decisão sobre a existência ou não de seres em gestação fica por conta do hospital.

Mais do que uma ideia de quando começa a vida, nossa experiência, com o aborto espontâneo na $11^{\mathrm{a}}$ semana, indicou certo consenso de que aquilo que se extraía por meio de uma operação em tudo similar ao aborto era apenas substância da mãe. A operação foi rápida, só uma noite no hospital para recuperação. Tudo foi feito como se se tratasse de uma operação realizada em Sônia, pois não se considerava ser ela um tipo de intervenção que lidava com dois seres. Ao final da operação, a obstetra perguntou-me se eu gostaria que fosse conduzida uma análise sobre os motivos do aborto espontâneo no "material" (com o que concordei). Uma vez fora do útero, o que era um feto passou a ser apenas um "material", algo extraído da mãe, mas que não era um ser. Era sua substância, uma espécie de despejo orgânico.

Para os pais, essa experiência contrastava com o início de um processo relacional de construção de pessoalidade. Embora o estágio da gravidez fosse inicial, já naquele momento um espaço para o "bebê" havia sido criado no seio das relações articuladas pelos pais: a família se preparava para um novo membro, os amigos estavam cientes da gravidez, e o casal vinha construindo estratégias de inserção do bebê no núcleo familiar. Pensava-se na organização do quarto, em possíveis nomes, que tipo de carro seria o ideal para comportar três crianças etc. Um enorme investimento emocional, interrompido pela falha do desenvolvimento natural do feto.

Mas o pouco tempo de gravidez e o fato de o aborto ter sido espontâneo indicavam certa despreocupação com essa produção social da pessoa, em suas 
fases primárias. A fácil transformação em dejeto do corpo da mulher daquilo que era uma "pessoa-em-construção" é, para os pais, um sintoma a mais da lógica substantiva aplicada ao desenvolvimento do feto: a individualidade construída de forma natural no processo de desenvolvimento é ligada a um quantum de substância, antes do qual não temos indivíduo, mas substância da mulher. Depois desse reconhecimento numa linha de evolução, há o período liminar que o prematuro representa: um desenvolvimento incompleto em termos naturais. E, por fim, há os nascimentos a termo, nos quais o processo de desenvolvimento da individualidade natural coincide com a construção relacional da pessoalidade. Destaca-se a questão do peso como uma espécie de fato social total da UTI, pois tudo gira ao seu redor. O tempo, ali, se conta em gramas.

No caso do aborto espontâneo, a falta de substância do feto impede que a sua portadora (a mulher) se transforme em mãe, passagem que, quando não realizada, possibilita o despejo do material fetal sem problemas legais. A incompletude do processo de desenvolvimento não muda o estado da portadora do feto, não a transforma em mãe e, portanto, não se pode falar da existência de um segundo ser em seu interior.

Estas três narrativas constituem o campo a ser analisado. A descrição já adiantou as principais questões que serão a seguir esmiuçadas: o descompasso entre processos de individualização e pessoalização, a UTI como uma espécie de máquina reguladora de uma rearticulação entre ambas, tudo isso baseado numa lógica substantiva que deve ser atrelada ao desenvolvimento natural do feto.

\section{A lógica substantiva}

Os casos descritos acima, numa reflexão comparativa, indicam que, embora as tecnologias reprodutivas tenham adiantado o processo de individualização até o próprio embrião, há uma lógica nativa que atrela individualização à substância. Na UTI, abaixo de certo peso (de quantum de substância), não existe pessoa, pois não existe indivíduo separado da mãe. O argumento não é uma contestação das discussões sobre o embrião, mas a apresentação de outra dimensão relativa à construção da individualização que não tem sido muito considerada no debate contemporâneo: a dimensão da substância. O caso da curetagem apresenta um contraponto, configurando uma espécie de despejo de material da mãe e não de um aborto, ou seja, mesmo legalmente, o aborto só pode existir a partir de determinado quantum de substância. ${ }^{8}$ Nesse caso, como na UTI neonatal, antes de determinado peso, o feto é considerado parte e substância da mãe. 
Vemos que o caso aqui narrado pode nos levar a matizar as perspectivas avançadas por Strathern, pois se trata-se apenas de pessoas não relacionais, remetendo-se tão somente ao desenvolvimento natural, não deveria haver choque entre futuros pais e funcionários da UTI neonatal. Se os pais reconhecessem como categoria de pessoa apenas o processo natural de desenvolvimento do embrião, seria natural aceitar a suspensão de individualidade produzida pelo UTI, ao tratar do bebê como substância da mãe. Mas o fato é que o processo de constituição de pessoalidade disparado pelos pais é, sim, um processo relacional, mediado por relações sociais de toda ordem, ${ }^{9}$ e que entra em conflito com as categorias construídas pelo hospital e pelas trabalhadoras da UTI. O hospital segue a lógica exposta por Strathern, que poderíamos chamar de "científica". As funcionárias inserem uma noção de substância na ideia de desenvolvimento natural do feto: até certo peso ele não tem individualidade, depois de certo limite ele a recebe. Quando isso se dá, o índice de aceitação daquele ser como pessoa é a adoção do nome, o ícone por excelência do processo relacional de construção de pessoalidade disparado pelos pais. Diríamos que as funcionárias medeiam uma contradição entre um discurso oficial-estatal expresso por meio do hospital e as intensidades construídas pela família do prematuro.

Isto não obscurece o fato de que, nas esferas do discurso público mediado por perspectivas científicas, a biologia predomina e a pessoa começa quando uma circunstância biológica se inicia, ou seja, o predomínio crescente da biologia levará à conjunção de individualidade e pessoalidade no surgimento, concomitante, do embrião como detentor de direitos. Nas NTR, Strathern aponta que as relações sociais parecem contingentes, mas, do meu ponto de vista, esta é apenas parte da história, aquela relativa aos discursos públicos. Os dados levantados pelo meu trabalho de campo compulsório indicam que relações sociais não são contingentes para os sujeitos envolvidos no processo.

Nos discursos públicos temos o embrião, depois a pessoa: no prematuro há um descompasso, pois já há mais pessoalidade que individualidade. Strathern demonstra que a individualidade não é um processo relacional, mas um ponto qualquer no desenrolar do desenvolvimento natural, isto é, a natureza cuida de produzir o indivíduo; a sociedade, a pessoa. O que Strathern não diz, mas podemos inferir, é que a individualidade é uma questão de substância. Em determinado momento, já com certo quantum, pode-se dizer que o embrião tem substância suficiente para ser considerado um indivíduo único e indivisível. Os processos de construção social de pessoalidade e natural de individualidade deveriam correr juntos, e o fizeram, antes das tecnologias relacionadas à reprodução humana (em um tempo passado, o 
indivíduo só existia se a criança nascesse viva, o sexo só era revelado no parto, e a produção social só se iniciava com o sucesso da gravidez). É possível imaginar, por outro lado, que sempre houve uma defasagem entre a individualidade e a pessoalidade - o nome só podia ser dado após o sexo ser conhecido, por exemplo - mas as tecnologias a aumentaram radicalmente. Essa defasagem causa tensões de todas as ordens.

Se associarmos este pensamento à constatação etnográfica de que o processo social deve ser acompanhado pelo desenvolvimento do feto (em termos substantivos), teremos uma explicação para a crise do prematuro, crise esta que se instala diante do prematuro, através do qual preceitos mais antigos (não tecnológicos) parecem operar: já há pessoalidade, mas não individualidade, pois o feto ainda não completou o desenvolvimento como manda a natureza, no sentido de se formar naturalmente como uma pessoa. Há uma assimetria entre a dimensão da individualidade (natural) e a da pessoalidade (social), sendo que a primeira acaba agindo como referência para a segunda, ou seja, o desenvolvimento natural torna-se referência para a construção da pessoa.

Ainda assim, talvez o processo de pessoalização não seja tão radicalmente sobreposto pela biologia e nem tão identificável com o embrião. O caso do prematuro indica a lógica substantiva da pessoalidade de forma exemplar, e a substância necessária para estabelecer uma pessoa no caso descrito é distinta da substância do que seja um embrião. Um reconhecimento tácito de tal distinção aparece nas regulações sobre o aborto espontâneo e o despejo do feto morto: um reconhecimento jurídico de que sem determinada quantidade de substância não há pessoa. Esse reconhecimento é traduzido em termos de tempo (relacionado ao desenvolvimento tido como natural do feto), ou seja, antes de $20^{10}$ semanas não pode haver pessoa, pois o processo de desenvolvimento não levou ainda ao acúmulo de determinado quantum de substância.

Na leitura de Strathern e de vários intelectuais contemporâneos, o processo de construção da pessoa é jogado para trás na constituição inicial do processo de individuação biológica. O caso que ilustro aqui trata, inversamente, de "defasagens futuras": quando a pessoa já existe socialmente e nasce incompleta de substância (prematura), há uma quebra cognitiva, gerando um processo de despessoalização temporária do bebê dentro da UTI neonatal. Ele não se desenvolveu naturalmente e, então, sua pessoalidade está suspensa - suspensão que dura o tempo que o bebê levar para recuperar substância considerada "adequada".

Obviamente, como afirma Strathern, "em circunstâncias normais o processo cumulativo do desenvolvimento humano e a complexificação não 
podem ser particionados, não se pode subtrair células da pessoa" (Strathern 1992:143). O caso narrado indica que não se subtrai substância da pessoa, mas pode haver um descompasso nos dois desenvolvimentos, quando um não acompanha o outro. A UTI neonatal é o lugar de "re-equação" dos dois processos, um suposto como natural e o outro claramente relacional - por isso ela suspende a pessoalidade por um tempo.

Isto explica porque entendo, a partir de certa perspectiva, o nascimento prematuro como o contrário do embrião: este tem, em algum momento, individualidade, mas não é pessoa; já o prematuro tem pessoalidade, mas não é indivíduo - não está pronto. Aqui, a noção de desenvolvimento é chave, pois em cada etapa é preciso haver correspondências - o embrião naturalmente se torna indivíduo e, depois, a sociedade o constrói como pessoa. Há correspondências entre estágios: a natureza primeiro, a sociedade depois. No prematuro, a falha da natureza (não substância) em correspondência com o desenvolvimento social impõe uma regressão — há pessoa demais para substância (individualidade) de menos. É uma equação entre desenvolvimento, indivíduo, pessoa e substância. Esta última é que dita a correlação entre os dois processos. Strathern tem razão ao atribuir à natureza a função quase biológica de constituição de pessoa na sociedade euro-americana, tanto que, quando a natureza não é ainda capaz de constituir completamente a pessoa, a sociedade precisa desfazer em parte o processo (uma reversão simbólica a um estado anterior, portanto).

A quantidade de substância é índice de pessoa, portanto, a pessoalidade está dada na naturalidade do processo: o problema é que esse processo "natural" é acompanhado pela sociedade, que vai tratando de consolidar a pessoa do bebê ao longo da gestação - com as confirmações médicas de que tudo vai bem no desenvolvimento natural. Mas havendo nele uma interrupção, estabelece-se a defasagem entre o processo social de construção e o natural, ao qual o primeiro estaria atrelado, como um trabalho social sobre o que é biológico, entrando em cena um lugar liminar de "desconstrução da pessoa" ou de "suspensão" do processo de construção da pessoa, a UTI neonatal. Mas, em última instância, é a naturalidade do processo que prevalece como relação na constituição da pessoa: há uma assimetria entre a noção de substância como índice de pessoalidade e a constituição social da pessoa, a favor do primeiro. Se a substância falta, tudo se complica e fica em suspenso.

Isto se evidencia no caso do prematuro, já que ele revela o descompasso entre fato natural e interpretação social e a assimetria entre um e outro. A criança sofre esse processo: a pessoa é construída, o indivíduo substantivo é natural. Quando o desenvolvimento natural falha (como no caso do prematuro), 
a construção tem que ser interrompida. Assim, a construção substantiva da pessoa é reconhecida, a social é construída. Ocorre uma inadequação de substância que se estende por um longo período após a saída de um bebê bastante "pequeno" da UTI neonatal, pois a família continua a lidar com o descompasso causado pela prematuridade. No caso de Gabriel, era preciso justificar constantemente o seu pouco tamanho em relação à idade, porque, embora tivesse, digamos, seis meses, ele continuava muito menor do que outras crianças desta faixa etária.

A defasagem substantiva continua a operar um problema de compreensão no que diz respeito a outras crianças: enfim, por que Gabriel era tão pequeno? E o trabalho dos pais era sempre o de adequar simbolicamente a idade de Gabriel. Embora tivesse seis meses, era como se tivesse quatro, já que nascera dois meses antes. Essa readequação quanto ao tamanho e ao desenvolvimento tido como natural continua sendo uma tarefa dos pais, operando agora como ajustadores de uma lógica substantiva. Esse dilema durou até cerca de 2 anos de idade, quando não se verificava mais um descompasso substantivo entre Gabriel e outras crianças e a questão do tamanho deixou de ser um problema. Já David não passou por essa crise de desajuste substantivo após a saída da UTI, pois ele era grande o suficiente para parecer uma criança "normal" para a sua idade. O caso dele foi inverso, nesse sentido: ele sempre foi grande demais para a UTI.

A incompletude do prematuro produzia ainda outra: a incompletude da mãe na UTI. Ela deu à luz sem completar o ciclo que a faria mãe. Com o filho na UTI neonatal, ela teve problemas com a amamentação e tudo apontava para o seu corpo como incapaz. A prova disto era o fato concreto da substituição do útero pela incubadora, como uma máquina social de readequar substância e pessoa. De certa forma, a mãe do prematuro é mutilada por não poder cuidar do filho (é menos mãe) e tenta-se superar isto nas visitas à UTI. Era uma obrigação de readequação da mãe, e qualquer falta era visivelmente reprovada pelas trabalhadoras, como se uma ausência impedisse o desenvolvimento da criança.

\section{Considerações finais}

Este artigo procurou refletir sobre a noção de pessoa dentro da UTI neonatal, a partir da experiência particular de viver dois partos de filhos prematuros. Chegamos à conclusão de que aquele espaço liminar executava uma espécie de equação entre processos divergentes de atribuição de categorias do ser dos bebês. Vimos que há uma lógica não relacional de 
construção da pessoa, que chamamos de individualidade, e outra, relacional, que chamamos de pessoalidade. Estas duas lógicas andam em separado quando nasce um bebê prematuro, e o hospital serve como uma máquina de adequação, tentando suspender um processo (o social) enquanto outro (considerado não social) se desenvolve "naturalmente" com o auxílio de toda a tecnologia médica.

Considerar o valor de noções relacionais de pessoa no universo "euro-americano" não é novidade. Vários autores atentam para este fato. Pina-Cabral, por exemplo, afirma que "(s)e estudarmos etnograficamente as utilizações do conceito de pessoa nas sociedades europeias - nomeadamente por relação à constituição da pessoa familiar [...] — seremos levados a verificar que a polarização entre uma pessoa individual ocidental e uma pessoa relacional não ocidental é patentemente exagerada e enganadora" (2005:10). Assim, contrastar as narrativas públicas sobre a emergência da pessoa em embriões na sociedade ocidental com etnografias de noções relacionais de pessoa não é em si algo original.

Porém, indicar o funcionamento e a articulação entre esses dois processos, ou seja, a construção de uma pessoa individual — nos termos de PinaCabral - e uma pessoa relacional pode ser bastante elucidativo. No caso dos prematuros, vimos que é em função de uma noção nativa de "substância", articulada a uma verdadeira ontologia, que podem ser conectados os dois processos, que eu chamei de atribuição de individualidade e de pessoalidade. O prematuro impõe uma ruptura na articulação entre eles. A rearticulação é promovida por uma lógica substantiva, a de atribuição de um marco para a reemergência da pessoalidade. Este marco é a evidência de certa quantidade de substância, que seria algo como um avanço no desenvolvimento "natural" do bebê. Ao se identificar nesse desenvolvimento um momento de adequação ao processo social de pessoalização, as funcionárias do hospital liberam a família e o bebê para que este siga no processo de constituição da nova pessoa, uma vez que os dois atributos necessários (individualidade e pessoalidade) foram reordenados pela substância.

Num debate com Pina-Cabral, vale lembrar que o momento efetivo dessa reequação ocorreu através de um gesto simbólico, quando uma das funcionárias da UTI neonatal escreveu, na parte de cima da ficha de identificação do RN Sônia Silva, o nome que nós tínhamos escolhido para ele: Gabriel. É importante frisar que no momento em que a substância do RN Sônia Silva promoveu-o a pessoa, o índice desse novo ser passou a ser o nome próprio.

Se a pesquisa sobre nomes desenvolvida por este autor ${ }^{11}$ tem levado a reflexões sobre a pessoa relacional em diversos contextos, principalmente 
lusófonos, este artigo procurou pensar a articulação empírica entre aspectos não relacionais e relacionais da noção de pessoa em um contexto "ocidental", ou ainda, lusófono. Essa articulação se deu através de uma lógica substantiva, simbolicamente ordenada pela atribuição de nomes, ou seja, da passagem de um nome não substantivo (o antinome RN Sônia Silva), que indicava o bebê como extensão da mãe, para um nome substantivo (Gabriel).

Recebido em 21 de fevereiro de 2011

Aprovado em 22 de fevereiro de 2013

Igor José de Renó Machado é coordenador do Programa de Pós-Graduação em Antropologia Social da UFSCar. E-mail: < igorreno@gmail.com>

\section{Notas}

- Uma versão deste artigo foi apresentada no $32^{\circ}$ Encontro Anual da Anpocs, 2008, em Caxambu.

${ }^{1}$ Os casos acompanhados tratam de um casal.

${ }^{2}$ A noção de "Ocidente" ou "Euro-América" é obviamente algo discutível. O que exatamente é o Ocidente? Mesmo assim, ela é largamente utilizada por autores europeus e americanos. De um ponto de vista sul-americano, fico sempre em dúvida se a categoria "Euro-América" de Strathern inclui o Brasil, por exemplo. Para a operacionalização deste texto, tomo a categoria "Ocidente" em sentido bem genérico, significando países relacionados intimamente à história europeia (mesmo que seja por colonização). Ver Salem (1997:79) para uma reflexão sobre o tema relacionada à questão das NTR.

${ }^{3}$ Tradução do autor.

${ }^{4}$ A narrativa algumas vezes passa para a terceira pessoa por ter se tratado de uma experiência do casal. As implicações emocionais dos eventos narrados são deixadas de lado, para uma futura reflexão mais elaborada. Também as consequências "etnográficas" deste tipo de narrativa serão objeto de outro artigo: o que se pode tirar de rendimentos antropológicos de experiências "autoetnográficas". Por outro lado, optei por mudar o nome das pessoas diretamente envolvidas, a fim de minimizar quaisquer implicações futuras da exposição desta história particular. 
${ }^{5}$ Cf. Pina-Cabral (2005).

${ }^{6} \mathrm{O}$ conjunto de trabalhadoras incluía auxiliares de enfermagem, técnicas de enfermagem, enfermeiras. Todas mulheres. Além disso, havia sempre uma neonatologista de plantão (apenas dois entre oito eram homens). Havia sempre um conjunto de quatro ou cinco trabalhadoras mais a/o neonatologista.

${ }^{7}$ Lei de Registros Públicos (Lei 6015 de dezembro de 1973; artigo 53).

${ }^{8}$ Poderíamos pensar que essa percepção da substância remeta a uma ideia de possibilidade da vida extrauterina.

${ }^{9}$ Note-se que esses processos não são de forma alguma universais ou semelhantes. Há variadas formas de construir pessoalidade para fetos e bebês. Para um olhar sobre populações indígenas, ver o exemplo Piro descrito por Gow (1997).

${ }^{10} \mathrm{O}$ número de semanas a partir do qual se é obrigado a registrar o bebê, mesmo que natimorto, varia entre 20 e 28 semanas, conforme a fonte pesquisada.

${ }^{11}$ Esta pesquisa resultou na organização da coletânea de Pina Cabral e Viegas (2007) e no dossiê sobre nomes de pessoa, publicado na revista Etnográfica (2008).

\section{Referências bibliográficas}

CHAZAN, Lilian Krakowski. 2007. “Meio quilo de gente": um estudo antropológico sobre o ultrassom obstétrico. Rio de Janeiro: Editora da Fiocruz.

DUARTE, Luiz Fernando Dias. 1986. Da vida nervosa nas classes trabalhadoras urbanas. Rio de Janeiro: Jorge Zahar Editor/CNPq.

. 1983. "Três ensaios sobre pessoa e modernidade". Boletim do Museu Nacional, 41.

DUMONT, Louis. 1985. Ensaios sobre o individualismo: uma perspectiva antropológica sobre a ideologia moderna. Rio de Janeiro: Rocco.

ETNOGRÁFICA. 2008. 12(1). Lisboa.
GOLDMAN, Márcio. 1996. "Uma categoria do pensamento antropológico: a noção de pessoa". Revista de Antropologia, 39(1):21-38.

GOW, Peter. 1997. "O parentesco como consciência humana: o caso dos Piro". Mana. Estudos de Antropologia Social, 3(2):39-65.

LÉVI-STRAUSS, Claude. 1989. O pensamento selvagem. Campinas: Papirus.

LUNA, Naara. 2007."A personalização do embrião humano: da transcendência na biologia". Mana. Estudos de Antropologia Social,13(2):411-440. . 2001. "Pessoa e parentesco nas novas 
tecnologias reprodutivas". Revista Estudos feministas, 9(2):389-413.

PINA CABRAL, João de \& VIEGAS, Susana de Matos (eds.).2007. Nomes: género, etnicidade e família. Coimbra: Almedina.

PINA CABRAL, João de. 2005. "O limiar dos afectos: algumas considerações sobre nomeação e a constituição social de pessoas". Conferência de abertura do PPGAS/Unicamp, 2005. Disponível em www.ceao.ufba.br/fabrica/txts/cabral/limiar.doc. Publicado em italiano como "La sogliadegliaffetti: considerazioni sull'attribuzionedel nome e lacostruzionesocialedella persona". Annuario di Antropología, 5(6):151-172.

SALEM, Tania. 1997. "As novas tecnologias reprodutivas: o estatuto do embrião e a noção de pessoa". Mana. Estudos de Antropologia Social, 3(1):75-94.

SEEGER, Anthony; DAMATTA, Roberto \& VIVEIROS DE CASTRO, Eduardo B. 1979. "A construção da pessoa nas sociedades indígenas brasileiras". Boletim do Museu Nacional, 32:2-19.

STRATHERN, Marilyn. 1992. Afternature. Cambridge: Cambridge University Press. 


\section{Resumo}

A partir de uma etnografia numa UTI neonatal, articulo uma reflexão sobre a relação entre corpo, substância, subjetividade e pessoa que era ali atribuída aos bebês prematuros. A intenção é demonstrar que há um cálculo inconsciente de substancialização do bebê, ou seja, a ideia de que a partir de determinado peso há uma existência reconhecida do bebê enquanto pessoa dotada de subjetividade. Antes dessa linha demarcatória de atribuição de existência social, o prematuro é tratado como uma espécie de apêndice da mãe, sem subjetividade. Busca-se fazer uma reflexão substantiva que depende da formação do corpo para a atribuição de pessoalidade, contrastando tal "fato etnográfico" com as discussões teóricas que indicam um processo de antecipação sistemática da atribuição de pessoalidade, possibilitado pelo avanço das tecnologias reprodutivas.

Palavras-chave Pessoa, Indivíduo, Substância, Embrião, Prematuro, UTI neonatal.

\section{Abstract}

Based on ethnography undertaken in a neonatal intensive care unit, I reflect upon the relationship between body, substance, subjectivity and person. My intention is to demonstrate the medical staff's unconscious calculation of "substancialization" of the baby. This is the idea that from, based upon a baby's weight, it can be recognized as a person endowed with subjectivity. Before this attribution of social existence, the premature newborn infant is seen as the mother's subjectivity-less appendix. I aim reflect here upon the formation of the body as a prerequisite for the formation of personhood. I compare my ethnographic data with theoretical approaches that indicate a process of systematic anticipation of the attribution of personhood, which have been made possible by advances in reproductive technologies.

Key words Person, Individual, Substance, Embryo, Premature newborn infant, Neonatal ICU. 